the option of renal transplantation from living donors should be more widely discussed.

We thank the many clinicians and transplant coordinators who contributed to this survey and Mrs Carole Austin, who typed the manuscript.

\footnotetext{
1 Bradley BA, Selwood NH. The natural history of transplantable kidneys. Health Trends 1983;15:25-7.

2 United Kingdom Transplant Service. Annual report. Bristol: UKTS, 1988.

2 United Kingdom Transplant Service. Annual report. Bristol: UKTS, 1988. Nephrol Dial Transplant 1987;2:475-87.

4 US end stage renal disease program: selected 1984 statistics. Contemporary Dialysis and Nephrology 1985;12:11.

5 Bay WJ, Lee AH. The living donor in kidney transplantation. Ann Intern Med 1987; 106:719-27.

6 Peto R. Experimental survival curves for interval-censored data. Applied Statistics 1973;23:86-91

7 Working Party on the Supply of Donor Organs for Transplantation. Report. London: Department of Health and Social Security, 1987.

8 Morris PJ. Results of renal transplantation. In: Morris PJ, ed. Kidney transplantation. London: Academic Press, 1984:547-9.

9 Brunner FP, Broyer M, Bryner H, et al. Survival on renal replacement therapy: data from the EDTA registry. Nephrol Dial Transplant 1988;2: 109-22.

10 Salvatieria D, Vincetti F, Amend $\mathrm{W}$, et al. Deliberate donor-specific blood transfusions prior to living related renal transplantation. Ann Surg 1980;192: transfusion.

11 Taylor RMR, Ting A, Briggs JD. Renal transplantation in the United Kingdom and Ireland - the centre effect. Lancet 1985; ; :798-802.

2 Anonymous. Living related kidney donors [Editorial]. Lancet 1982;ii:696.

13 Kahan BD, Mickey R, Flechner SM, et al. Multivariate analysis of risk
}

factors impacting on immediate and eventual cadaver allograft survival in cyclosporin-treated recipients. Transplantation 1987;43:65-70.

14 Gilks WR, Bradley BA, Gore SM. Predicting waiting time for a beneficially matched graft. Transplant Proc 1987;19:3640-1.

15 Kutner NG, Brogan D, Kutner MH. End-stage renal disease treatment modality and patients' quality of life. Am $\mathcal{F}$ Nephrol 1986;6:396-402.

16 Maher ER, Curtis JR. Mortality and morbidity of long term haemodialysis. Lancet 1987; ;:452-3.

17 Wood IT, Mallick NP, Wing AJ. Prediction of resources needed to achieve the national target for treatment of renal failure. Br Med $\mathcal{Y} 1987 ; 294: 1467-70$.

18 Sherwood T, Riutu M, Chisholm GD. Renal angiography problems in live kidney donors. Br f Radiol 1978;51:99-105.

19 Spital A, Spital M, Spital R. The living kidney donor. Arch Intern Med 1986;146:1993-6.

20 Ogden DA. Consequences of renal donation in man. Am $\mathcal{f}$ Kidney Dis 1983;2:501-11.

21 Weiland D, Sutherland DER, Chaveris B, Simmons RL, Ascher NL, Najarian JS. Information on 628 living related kidney donors at a single institutio with long term follow-up in 472 cases. Transplant Proc 1984;16:5-7.

22 De Marco T, Amin M, Harty JJ. Living donor nephrectomy: factors influencing morbidity. $\mathcal{O}$ Urol 1982;127:1082-3.

23 Davison JM, Uldall PR, Walls J. Renal function studies after nephrectomy in renal donors. Br Med J 1976; i: 1050-2.

24 Tapson JS. Prognosis after donor nephrectomy: an update. Int $\mathcal{f}$ Artif Organs 1987;10:9-13.

25 Tapson JS, Mansy $H$, Marshall SM, Tisdall SR, Wilkinson R. Renal functional reserve in kidney donors. $Q \mathcal{F}$ Med 1986;232:725-32.

26 Morris PJ, Sells RA. Paying for organs from living donors. Lancet 1985; i: 1510 . 27 Council of the Transplantation Society. Commercialisation in transplantation: the problems and some guidelines for practice. Lancet 1985;ii:715-6.

28 Haberdal M, Sert S, Aybasti N, et al. Living donor kidney transplantation. Transplant Proc 1988;20:353-5.

(Accepted 23 November 1988

\title{
Human gastric mucosal bleeding induced by low dose aspirin, but not warfarin
}

Peter J Prichard, Gerry K Kitchingman, Robert P Walt, Tawfique K Daneshmend, Christopher J Hawkey

\section{Abstract}

Objective-To investigate the suitability of treatment with low dose aspirin or warfarin, or both, as possible prophylaxis against cardiovascular disease by determining the effect on gastric mucosal bleeding.

Design-Randomised crossover trial.

Setting-Academic department of therapeutics.

Subjects-Twenty healthy male volunteers aged 19-22.

Interventions-On separate occasions and in randomised order all subjects received aspirin $75 \mathrm{mg}$, warfarin, or aspirin $75 \mathrm{mg}$ combined with warfarin. Each treatment was given for 12 days or (when warfarin was used) for longer if necessary until the international normalised ratio of the prothrombin time was stable at 1.4-1.6.

End point-Loss of blood over 10 minutes into gastric washings.

Measurements and main results-Bleeding over 10 minutes into gastric washings under baseline conditions and after five days, and at end of each regimen of treatment. Aspirin $75 \mathrm{mg}$ increased bleeding from 0.60 (95\% confidence interval 0.36 to 0.99$) \mu \mathrm{l} / 10$ minutes to $1.26(0.71$ to 2.25) $\mu \mathrm{l} / 10$ minutes at five days, with no evidence of either progressive change or adaptation thereafter. Warfarin had no effect on bleeding either alone or when combined with aspirin.

Conclusions-Aspirin $75 \mathrm{mg}$ causes gastric mucosal bleeding. Low dose warfarin neither induces gastric mucosal bleeding nor enhances that caused by aspirin.

\section{Introduction}

Thrombosis is a common feature of both unstable angina and death from ischaemic heart disease and unstable angina. This may be related to enhanced platelet activity ${ }^{2}$ or increased amounts of fibrinogen and factor VII, which have been associated with fatal and non-fatal ischaemic heart disease. ${ }^{3-6}$ The effect that aspirin has on the function of platelets has been shown to reduce morbidity and mortality in patients with unstable angina and myocardial infarction and to be probably beneficial in the primary and secondary prevention of myocardial infarction. ${ }^{7-20}$ Trials have tended to use progressively lower doses of aspirin as these cause maximum inhibition of synthesis of thromboxane by platelets, have a minimal effect on synthesis of prostacyclin by vessel walls, and substantially prolong the bleeding time..$^{21-23}$ For these reasons doses of aspirin of less than $100 \mathrm{mg}$ a day might theoretically be more effective than higher doses, but for the same reasons they might render patients prone to bleeding that is also seen with higher doses. ${ }^{7-20}$

Anticoagulant treatment with warfarin has also been used to prevent myocardial reinfarction. Although it is probably beneficial, ${ }^{24}$ its continued use causes a progressive increase in bleeding. ${ }^{25}$ An alternative approach is to use lower doses to normalise the increased activity of factor VII found in patients prone to vascular disease,${ }^{6}$ but whether this would cause less bleeding is as yet unproved.

Possibly optimum benefit would accrue from combining low doses of aspirin and warfarin, and this approach is to be investigated by the Medical Research Council in a large community based study. ${ }^{26}$ Because a combination of treatments has the potential to enhance harm (particularly gastrointestinal bleeding) as much as benefit we investigated the effect of low doses of aspirin and warfarin, alone and in combination, on gastric mucosal bleeding.

\section{Subjects and methods}

Twenty healthy non-smoking male volunteers aged 19 to 22 participated in the study. They did not have a 
history of dyspepsia, easy bruising or bleeding, or intolerance to aspirin or warfarin. Normal blood counts, platelet counts, and coagulation profiles were required before the study. The subjects did not take any drugs other than those related to the trial and did not drink alcohol during the periods of treatment. The protocol was approved by Nottingham Medical School's ethical committee. All subjects gave informed written consent.

Each subject was studied under baseline conditions and during and after each of three treatments. (1) Aspirin $75 \mathrm{mg}$ a day was given for 12 days. (2) Warfarin was given at an initial dose of $2 \mathrm{mg}$ a day, which was adjusted according to the international normalised ratio of the prothrombin time every two to three days, and continued for at least 12 days or until the ratio was $1.4-1.6$ for at least two consecutive readings. (3) Aspirin $75 \mathrm{mg}$ a day and warfarin were combined. At the end of a period of monotherapy with one of these drugs the other drug was added and both drugs were continued for a further 12 days or until the international normalised ratio of the prothrombin time was 1.4-1.6 for at least two consecutive readings.

The subjects were randomised to four cohorts, which received the treatments in different orders. The figure shows two of the schedules of treatment; the other two schedules were similar, but period 1 and periods 2 and 3 were reversed. The subjects were studied after five days and at the end of each of the three periods of treatment. In addition, baseline measurements were made before dosing in 10 subjects and after the completion of treatment in the other 10 . On another occasion (not randomised) subjects were given aspirin $600 \mathrm{mg}$ four times a day for five days for comparison with low dose aspirin.

On each day that subjects were tested they underwent orogastric intubation with a 16 French gauge Salem sump tube (Sherwood, Belgium) two hours after they had taken the drug. Gastric juice was aspirated while the subjects rested, and the stomach was rinsed three times by the rapid introduction, dispersal, and aspiration of $100 \mathrm{ml}$ distilled water. A 10 minute collection then began. After five minutes $2 \mathrm{mg}$ phenol red in $15 \mathrm{ml}$ distilled water was introduced and dispersed around the stomach. After nine minutes $100 \mathrm{ml}$ distilled water was instilled, dispersed, and aspirated at 10 minutes. After two more rapid rinses a second 10 minute collection began, and after two further rapid rinses a third 10 minute collection was performed. Whenever water or phenol red was introduced subjects performed a standardised series of manoeuvres to ensure dispersal of the liquid within the stomach.

The volume and $\mathrm{pH}$ of, and concentrations of blood and phenol red in, each of the timed aspirates were measured. The $\mathrm{pH}$ was measured with a glass

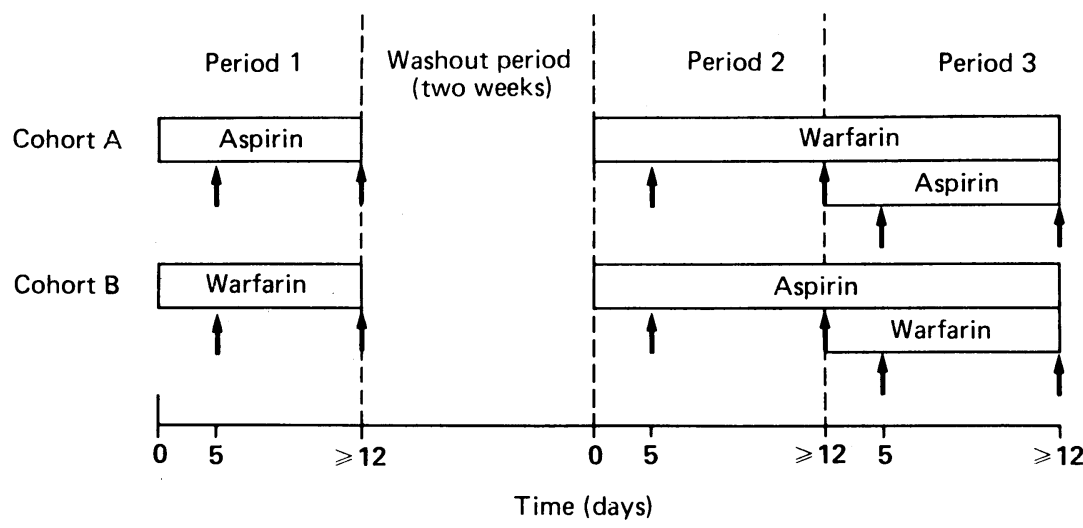

Examples of two schedules of treatment. Each cohort contained five subjects; other two schedules were as for $A$ and $B$ but with periods 2 and 3 before period 1 . Arrows show when subjects were studied, at days 5 and 12 or when international normalised ratio of prothrombin time stabilised
Blood loss ( $\mu$ l/10 minutes) into gastric washings for 20 subjects treated with warfarin or aspirin, or both. Numbers are geometric means $(95 \% \text { confidence intervals })^{\star}$

\begin{tabular}{llc}
\hline & \multicolumn{2}{c}{ Day } \\
\cline { 2 - 3 } & \multicolumn{1}{c}{5} & \multicolumn{1}{c}{ Final } \\
\hline Warfarin & $0.60(0.33$ to $1 \cdot 10)$ & $0.58(0.35$ to 0.99$)$ \\
Aspirin 75 mg a day & $1.26(0.71$ to 2.25$)$ & $1.24(0.56$ to 2.75$)$ \\
Warfarin and aspirin & $1.11(0.58$ to $2 \cdot 13)$ & $0.93(0.46$ to 1.87$)$ \\
Aspirin 2.4 g a day & $8.38(5.13$ to 13.70$)$ & \\
\hline
\end{tabular}

^Baseline blood loss $0.60(0.36$ to 0.99$) \mu \mathrm{l} / 10$ minutes.

electrode (Corning). Phenol red was measured spectrophotometrically at $560 \mathrm{~nm}$ after a $1 / 4$ dilution of gastric aspirate with ammonium hydroxide. ${ }^{27}$ Blood was measured by using the peroxidase activity of haemoglobin to oxidise $o$-tolidine to produce a colour reaction. ${ }^{27} 28$ For this assay aliquots of gastric aspirate $(0.2 \mathrm{ml})$ were mixed with $1.8 \mathrm{ml}$ citrate buffer $(12.6 \mathrm{~g}$ citrate monohydrate and $9.8 \mathrm{~g}$ trisodium citrate $/ \mathrm{l}$, pH 3.8 at room temperature $)$ and $o$-tolidine $(2 \mathrm{~g} / 100 \mathrm{ml}$ glacial acetic acid). Forty five seconds later $0.4 \mathrm{ml}$ hydrogen peroxide ( 20 volumes $/ 100 \mathrm{ml}$ ) was added and the solution mixed gently. The rate at which a blue-green colour developed was measured by the difference in absorbance, measured at $640 \mathrm{~nm}, 30$ and 60 seconds after hydrogen peroxide was added. Samples were compared with standards prepared from the subjects' blood.

Statistical methods-Loss of gastric mucosal blood in each timed aspirate was calculated after correction for recovery of phenol red. Data from any aspirate from which less than $25 \%$ of the phenol red was recovered were rejected, and the medians of the remaining samples were used for analysis. Data on bleeding were logarithmically transformed to approximate a normal distribution. The changes in bleeding after treatment with aspirin $75 \mathrm{mg}$ or warfarin, or both, from baseline values were analysed by two way factorial analysis of variance. Values for $\mathrm{pH}$ were assessed non-parametrically by Friedman two way analysis of variance. Other comparisons were by paired Student's $t$ test. A value of $\mathrm{p}<0.05$ (two tailed) was regarded as significant. Based on the variance of blood loss under baseline conditions the study had the power $(\alpha=0.05,1-\beta=0.8)$ to detect a doubling in rates of mucosal bleeding to $1 \cdot 2 \mu \mathrm{l} / 10$ minutes. $^{29}$

\section{Results}

The subjects tolerated the treatment regimens and the study procedure well and did not experience adverse effects. One subject, however, was withdrawn from the study because of erratic attendance especially while taking warfarin. When the data from all the cohorts for each period of the different regimens were combined the mean final dose of warfarin needed to achieve an international normalised ratio of the prothrombin time in the target range of $1 \cdot 4-1 \cdot 6$ was $4 \cdot 0$ ( $95 \%$ confidence interval 3.4 to $4 \cdot 6$ ) $\mathrm{mg}$ a day without aspirin and $4.0(3.4$ to $4 \cdot 7) \mathrm{mg}$ a day with aspirin. At the first orogastric intubation during warfarin treatment the international normalised ratio was $1 \cdot 41$ (1.30 to 1.52 ), and during treatment with warfarin combined with aspirin it was $1.49(1.34$ to 1.64$)$. At the second intubation at 12 days or more it was $1.46(1.41$ to 1.52$)$ and $1.50(1.46$ to 1.54$)$ respectively. These values were achieved at 11 (interquartile range 9-13) and $16(14-17)$ days respectively.

The table shows the amount of bleeding into the stomach with each of the treatments. Low doses of aspirin caused a significant increase in gastric bleeding $(p<0.05)$, but warfarin, by itself or in combination with the aspirin, had no significant effect. Although 
low doses of aspirin increased gastric bleeding by a factor of $1.9(95 \%$ confidence interval $1 \cdot 1$ to $2 \cdot 5)$, this was significantly less than the increase by a factor of 14 ( 8 to 26 ) caused by aspirin $2.4 \mathrm{~g}$ a day $(\mathrm{p}<0.01$ ) (table) There was no significant difference in the amount of bleeding at five and 12 days of any of the treatments By the end of the periods of combined treatments 10 subjects had received aspirin for more than 24 days (with warfarin during the second half of the period (figure)). The mean value for bleeding at the end of this period was $0.53(0.23$ to 1.17$) \mu \mathrm{l} / 10$ minutes, which was not significantly different from the corresponding value of $0.60(0.25$ to 1.42$) \mu \mathrm{l} / 10$ minutes seen in the same subjects after five days of the initial monotherapy with aspirin.

\section{Discussion}

Doses of aspirin in the range we used in this study are widely believed to be harmless to the gastric mucosa. Our study showed, however, that $75 \mathrm{mg}$ a day caused a significant increase in gastric mucosal bleeding. By contrast, warfarin in doses sufficient to raise the international normalised ratio of the prothrombin time by $50 \%$ did not seem to induce bleeding on its own or to enhance the bleeding seen with aspirin. An important feature of this study was that dosing continued over longer periods (up to two weeks for each treatment alone and four weeks in which combination treatment followed monotherapy) than in most other studies of acute injury due to aspirin. This allowed us to address a critical question: whether the risk of bleeding increased with time or, alternatively, whether it decreased by a process of adaptation. With high doses of aspirin and indomethacin there is evidence that mucosal injury, measured by bleeding and changes on endoscopy, is greatest in the first week of ingestion and that adaptation occurs with prolonged ingestion. . $^{30-32} \mathrm{~A}$ recent report suggested that time to adaptation is dose dependent, being of two or three weeks with aspirin $650 \mathrm{mg}$ twice daily and two to eight weeks with $650 \mathrm{mg}$ thrice daily. ${ }^{32}$ Our study showed quite clearly that neither progressive bleeding nor adaptation occurred after five days with continued ingestion of aspirin $75 \mathrm{mg}$ a day for up to one month.

An important factor in the success of any regimen of warfarin proposed for widespread use is its simplicity and safety. We used an extremely cautious regimen because there was little information available to guide the choice of dose. In practice, the final dose was $2 \cdot 5-7.0 \mathrm{mg}$ in all subjects and $3.5 \mathrm{mg}$ in all but five of the satisfactory dosing periods. Thus initial stabilisation on $3 \mathrm{mg}$ a day for one to two weeks with subsequent adjustment of the dose would take most subjects into or near the desired therapeutic range easily, rapidly, and safely.

A reasonable criticism of the present study is that we used young rather than elderly subjects. In the few studies that have compared experimental gastrointestinal bleeding from aspirin in different age groups there was no evidence that bleeding was greater in the elderly. ${ }^{334}$ As far as can be determined, therefore, our data probably apply to those older people in whom prophylaxis with aspirin and warfarin is most appropriate and risk of haematemesis and melaena is most significant, ${ }^{35}$ but this can be confirmed only by direct investigation in this age group.

Taken in context with other studies we have performed on aspirin, the acute injury measured by bleeding is clearly dose dependent. The bleeding associated with $75 \mathrm{mg}$ a day was some fivefold less than that associated with aspirin $1 \cdot 8-2 \cdot 4 \mathrm{~g}$ a day and about half that seen with aspirin $300 \mathrm{mg}$ a day. ${ }^{263637}$ As yet we are uncertain whether our data are relevant to long term treatment as results from recent trials of aspirin prophylaxis for cardiovascular disease have been conflicting. In a study of aspirin $500 \mathrm{mg}$ a day given to British doctors there was a significant increase in peptic ulceration (by $58 \%$ ) compared with that in controls and a non-significant increase in gastrointestinal bleeding, which led to the withdrawal of $2 \cdot 2 \%$ of subjects taking aspirin. ${ }^{17}$ By contrast, the brief interim report from the United States physicians' health study, in which $325 \mathrm{mg}$ aspirin on alternate days was used, stated that there was little evidence of these complications. ${ }^{16}$ In a third study, on the effect of aspirin on transient ischaemic attacks, aspirin $300 \mathrm{mg}$ and $1200 \mathrm{mg}$ daily (pooled data) was associated with increased dyspepsia and gastrointestinal bleeding. ${ }^{18}$ Although aspirin $300 \mathrm{mg}$ had a significantly lower effect than $1200 \mathrm{mg}$, it seemed to be associated with a higher incidence of bleeding than placebo, but the numbers were too small for significance to be determined.

Overall these studies suggest a dose dependent effect for aspirin given long term, which parallels the effects we have shown with short term treatment, with relatively little harm at doses below $300 \mathrm{mg}$ a day. The main problem with this interpretation is that the subjects in the United States physicians' study may have been unusually healthy as their incidence of cardiovascular disease was much lower than expected; in addition, those found on screening to have aspirin intolerance were excluded before randomisation. Our study showed that doses even as low as $75 \mathrm{mg}$ a day are harmful, though to a lesser extent than $300 \mathrm{mg}$ a day. Although higher doses of aspirin cause low rates of acute bleeding, they lead to major problems in some patients. Our study suggested that there is also a risk of such major problems with low dose aspirin but probably at a lower rate.

When patients present with bleeding peptic ulcers two quite different mechanisms are possible. Aspirin's gastroduodenal toxicity may lead to the development of peptic ulcers, some of which bleed. Alternatively, aspirin's ability to inhibit synthesis of thromboxane, interfere with aggregation of platelets, and prolong the bleeding time ${ }^{21-23}$ may cause silent ulcers to bleed. This remains a strong possibility as there is a significant increase in the relative risk of bleeding with short term or light aspirin consumption. ${ }^{38}{ }^{39}$ Aspirin's antiplatelet action may have been an important factor in the bleeding we observed as doses in the range we used cause maximum inhibition of synthesis of thromboxane by platelets. ${ }^{22}{ }^{23}$ Bleeding from sites other than the gastrointestinal tract has been associated with aspirin for up to five days after ingestion..$^{40}$ Of particular current concern is the unresolved possibility that low doses of aspirin may increase the incidence of haemorrhagic stroke. ${ }^{16-19}$

In contrast, although low dose aspirin causes gastric mucosal bleeding, there is no evidence that this is enhanced by concurrent use of low dose warfarin or that these doses have any effect alone. This was seen for treatment periods of up to one month, though we do not know whether this would apply to bleeding at other sites. Our data suggest that a trial of low dose aspirin combined with low doses of warfarin would carry no greater risk of gastrointestinal bleeding than that associated with low dose aspirin alone. As the risks of aspirin $75 \mathrm{mg}$ daily, though measurable, are small taking this with low dose warfarin may offer the best combination of therapeutic advantage and safety, and a trial of such treatment in patients at risk of vascular disease is warranted.

1 Davies MJ, Thomas A. Thrombosis and acute coronary artery lesions in sudden cardiac ischemic death. $N$ Engl $\mathcal{F}$ Med 1984;310:1137-40. Falk E. Unstable angina with fatal outcome: dynamic coronary thrombosis leading to infarction and/or sudden death. Circulation 1985;71:699-708.

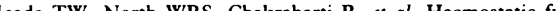


cardiovascular death: early results of a prospective study. Lancet 1980; $1050-4$.

4 Wilhelmsen L, Svardsudd K, Korsan-Bengstan K, et al. Fibrinogen as a risk factor for stroke and myocardial infarction. $N$ Engl f Med 1984;311:501-5. Stone MC, Thorpe JM. Plasma fibrinogen - a major coronary risk factor. I R Coll Gen Pract 1985;35:565-9.

6 Meade TW, Brozovic M, Chakrabarti R, et al. Haemostatic function and ischaemic heart disease: principal results of the Northwick Park heart study. Lancet 1986;ii:533-7.

7 Lewis HD Jr, Davis JW, Archibald DG, et al. Protective effects of aspirin against acute myocardial infarction and death in men with unstable angina. Results of a Veterans Administration cooperative study. $N$ Engl f Med 1983;309:396-403.

8 Cairns JA, Gent $M$, Singer J. Aspirin, sulfinpyrazone, or both in unstable angina. Results of a Canadian multicenter trial. $N$ Engl $\mathcal{F}$ Med 1985;313: 1369-75.

9 Elwood PC, Cochrane AL, Burr ML, et al. A randomised controlled trial of acetylsalicylic acid in the secondary prevention of mortality from myocardial infarction. Br Med f 1974;i:436-40.

10 Coronary Drug Project Research Group. Aspirin in coronary heart disease. f Chronic Dis 1976;29:625-42.

11 Breddin K, Loew D, Lechner K, Uberla K, Walter E. Secondary prevention of myocardial infarction: comparison of acetylsalicylic acid, phenprocoumon and placebo: a multicenter two-year prospective study. Thromb Haemost 1979:4:225-36:

12 Elwood PC, Sweetham PM. Aspirin and secondary mortality after myocardial infarction. Lancet 1979;ii:1313-5.

13 Aspirin Myocardial Infarction Study Research Group. A randomized, controlled trial of aspirin in persons recovered from myocardial infarction. TAMA 1980;243:661-9.

14 Persantin-Aspirin Reinfarction Study Research Group. Persantin and aspirin in coronary heart disease. Circulation 1980;62:449-61.

5 Patrono C. Aspirin for the prevention of coronary thrombosis: current facts and perspectives. Eur Heart $\mathcal{f}$ 1986; 7:454-9.

16 Steering Committee of the Physicians' Health Study Research Group. Preliminary report: findings from the aspirin component of ongoing physicians' health study. $N$ Engl f Med 1988;318:262-4.

17 Peto R, Gray R, Collins R. Randomised trial of prophylactic daily aspirin in British male doctors. Br Med f 1988;296:313-6.

18 Antiplatelet Trialists' Collaboration. Secondary prevention of vascular disease by prolonged antiplatelet treatment. BrMed f 1988;296:320-32.

19 UK-TIA Study Group. United Kingdom transient ischaemic attack (UK-TIA) aspirin trial: interim results. $\mathrm{Br}$ Med f 1988;296:316-20.

20 ISIS-2 Collaborative Group. Randomised trial of intravenous streptokinase, oral aspirin, both, or neither among 17,187 cases of suspected acute myocardial infarction. Lancet 1988;ii:349-60.

21 Patrono C, Ciabattoni G, Badrignani $P$, et al. Clinical pharmacology of platelet cyclo-oxygenase inhibition. Circulation 1985;72:1177-84.

22 Hanley SP, Bevan J, Cockbill SR, Heptinstall S. Differential inhibition by low dose aspirin of human prostacyclin synthesis and platelet thromboxane synthesis. Lancet 1981;i:969-71.

23 Pedersen AK, Fitzgerald GA. Dose related kinetics of aspirin. Pre-systemic acetylation of platelet cyclooxygenase. $N$ Engl F Med 1984;311:1206-11

24 Sixty Plus Reinfarction Study Group. Collaborative analysis of long-term anticoagulant therapy in elderly patients after myocardial infarction. Lancel $1980 ; \mathrm{i}: 203-9$.

25 Petitti DB, Strom BL, Melmon KL. Duration of warfarin anticoagulan therapy and the probabilities of recurrent thromboembolism and hemorrhage. Am J Med 1986;81:255-9.

26 Meade TW, Wilkes HC, Stirling Y, Brennan PJ, Kelleher C, Browne W. Randomised controlled trial of low dose warfarin in the primary prevention of ischaemic heart disease in men at high risk: design and pilot study. Eur Heart $f$ 1988;9:836-43.

27 Hawkey CJ, Simpson G, Somerville KW. Reduction by enprostil of aspirin nduced blood loss from human gastric mucosa. Am $\mathcal{Y}$ Med 1986;81(2A) $50-4$.

28 Fisher MA, Hunt JN. A sensitive method for measuring haemoglobin in gastric contents. Digestion 1976;14:409-19.

29 Machin D, Campbell MJ. Statistical tables for the design of clinical trials. Oxford: Blackwell Scientific Publications, 1987:86-8.

30 Graham DY, Smith JL. Aspirin and the stomach. Ann Intern Med 1986;104: 390-8.

31 Graham DY, Smith JL, Spjut HJ, Torres E. Gastric adaptation studies in humans during continuous aspirin administration. Gastroenterology 1988:95: 327-33.

32 Shorrock CJ, Rees DW. Effect of indomethacin on human gastroduodenal "mucus-bicarbonate" barrier. Gut 1987;28:A1411.

33 Pierson RN, Holt PR, Watson RM, Keating KP. Aspirin and gastrointestinal bleeding. 51 Chromate blood loss studies. Am f Med 1961;31:259-65.

34 Johnson PC. Gastrointestinal consequences of treatment with drugs in elderly patients. Am Geriatr Soc 1982;30(suppl):52-7

35 Somerville KW, Faulkner G, Langman MJSL. Non-steroidal antiinflammatory drugs and bleeding gastric ulcer. Lancet 1986;i:462-4.

36 Hawkey CJ, Somerville KW, Marshall S. Prophylaxis of aspirin induced gastric mucosal bleeding with ranitidine. Alimentary Pharmacological Therapy 1988;2:245-52.

37 Prichard PJ, Kitchingman GK, Hawkey CJ. Gastric mucosal bleeding: what dose of aspirin is safe? Gut 1987;28:A 1401.

38 Coggon D, Langman MJS, Spiegelhalter D. Aspirin, paracetamol, and haematemasis and melaena. Gut 1982;23:340-4.

39 Somerville KW, Prichard PJ, Faulkner G, Langman MJS. Aspirin and bleeding peptic ulcer. Gastroenterology 1987;92:1649.

40 Stuart MJ, Gross SJ, Elrad H, Graeber JE. Effects of acetylsalicylic acid ingestion on maternal and neonatal hemostasis. N Engl f Med 1982;307

(Accepted 2 December 1988)
Department of

Endocrinology, Charing

Cross Hospital, London, and Department of Medicine and Blood

Pressure Unit, Charing

Cross and Westminster

Medical School, London

W6 8RF

R J C Guy, MD, senior

registrar

Y Turberg, MD, senior house officer

R N Davidson, MD, senior

registrar

G Finnerty, MRCP, registrar

G A MacGregor, FRCP,

Wellcome senior lecturer

P H Wise, FRCP, consultant

endocrinologist

Correspondence to:

Dr Wise.

BrMed f 1989;298:496-7

\section{Mineralocorticoid deficiency in HIV infection}

\author{
R J C Guy, Y Turberg, R N Davidson, \\ G Finnerty, G A MacGregor, P H Wise
}

Infection with the human immunodeficiency virus (HIV) may result in adrenal necrosis and hence a deficiency of cortisol..$^{1-3}$ We report on a patient who developed severe sodium and water depletion because of a deficiency in production predominantly of mineralocorticoids. This important, easily treatable complication has probably been overlooked in patients infected with HIV.

\section{Case report}

A homosexual man aged 41 was admitted in April 1988 with a diagnosis of pneumocystis pneumonia. He was positive for HIV antibody. On admission his serum sodium concentration was $129 \mathrm{mmol} / \mathrm{l}$, potassium $4.7 \mathrm{mmol} / 1$, and urea $5.1 \mathrm{mmol} / \mathrm{l}$. Treatment with high doses of co-trimoxazole was started. His symptoms improved, and he was discharged 11 days later. His serum sodium concentration, however, had fallen during his admission and at discharge was $114 \mathrm{mmol} / \mathrm{l}$; serum potassium and urea concentrations were $5 \cdot 8$ $\mathrm{mmol} / \mathrm{l}$ and $9.7 \mathrm{mmol} / \mathrm{l}$, respectively. His serum cortisol concentration was measured, but the result was not available at discharge.

He was readmitted the next day complaining of feeling faint on walking, leg weakness, and breathlessness. Examination showed profound postural hypotension (blood pressure lying $120 / 80 \mathrm{~mm} \mathrm{Hg}$, un- recordable on standing); hyponatraemia (sodium concentration $110 \mathrm{mmol} / \mathrm{l}$ ) and hyperkalaemia (potassium concentration $6.7 \mathrm{mmol} / \mathrm{l}$ ) were more pronounced. Treatment with intravenous physiological saline relieved the symptoms, and Addison's disease was diagnosed provisionally. At this stage, however, the serum cortisol concentration in the sample obtained during the first admission was found to be $992 \mathrm{nmol} / \mathrm{l}$ (normal $250-550 \mathrm{nmol} / \mathrm{l}$ ). He was given oral dexamethasone $(0.5 \mathrm{mg}$ twice daily) and sustained release sodium $600 \mathrm{mg}$ three times daily, and an intravenous tetracosactrin test was performed (table). Plasma renin activity (after 10 minutes' sitting) was appreciably raised at $55 \mathrm{nmol} / \mathrm{l} / \mathrm{h}$ (normal $0.4-1.9 \mathrm{nmol} / \mathrm{l} / \mathrm{h}$ ), and plasma aldosterone concentration was $149 \mathrm{pmol} / \mathrm{l}$, which was low considering his high plasma renin activity. His 24 hour urinary excretion of sodium was $240 \mathrm{mmol}$. Treatment was changed to hydrocortisone $20 \mathrm{mg}$ in the morning and $10 \mathrm{mg}$ at night with fludrocortisone $0.1 \mathrm{mg}$ daily, which was increased to $0.2 \mathrm{mg}$ daily. Within 10 days this had corrected his postural hypotension (blood pressure lying $110 / 70 \mathrm{~mm}$ $\mathrm{Hg}$, standing $130 / 80 \mathrm{~mm} \mathrm{Hg}$ ) and restored his serum electrolyte concentrations to normal (sodium 136 $\mathrm{mmol} / \mathrm{l}$, potassium $3.6 \mathrm{mmol} / \mathrm{l}$, and urea $3.3 \mathrm{mmol} / \mathrm{l}$ ). Plasma renin activity fell to $5.8 \mathrm{nmol} / \mathrm{l} / \mathrm{h}$ and plasma aldosterone concentration remained low at $59 \mathrm{pmol} / \mathrm{l}$. $\mathrm{He}$ was negative for autoantibodies, and computed tomography of his adrenal glands showed a normal size and structure.

\section{Comment}

The patient's high plasma renin activity and low plasma aldosterone concentration with profound hyponatraemia indicated a severe mineralocorticoid 